\title{
Concurrent radiation therapy and docetaxel in adjuvant treatment of locally advanced breast cancer
}

\author{
Samy M. Algizawy ${ }^{1 *}$, Hoda H. Essa ${ }^{1}$ and AbdelNaser S. Zaid ${ }^{2}$
}

*Correspondence: samyalgiz@yahoo.com

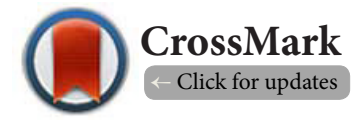

'Department of Clinical Oncology, Faculty of Medicine, Assiut University, Egypt.

${ }^{2}$ Department of General Surgery, Faculty of Medicine, Assiut University, Egypt.

\begin{abstract}
Purpose: To assess the safety and efficacy of the use of concurrent radiation therapy and docetaxel in adjuvant treatment of locally advanced breast cancer (LABC).

Patients and methods: Between February 2009 and January 2013, 62 patients with LABC who underwent primary mastectomy or neoadjuvant chemotherapy (FEC) followed by mastectomy at Assiut University Hospitals were entered into this trial. Three to five weeks after mastectomy or after the last dose of adjuvant FEC, patients were given concurrent chemoradiotherapy. Weekly intravenously docetaxel $\left(30 \mathrm{mg} / \mathrm{m}^{2}\right)$ was given over 9 weeks.

Results: The median follow-up for all patients is 32 months (range 12-63). Forty-eight patients $(77.4 \%)$ remain alive, 12 patients $(19.4 \%)$ died due to breast cancer, and $2(3.2 \%)$ from other nonrelated causes. The 3-year rate of local recurrence free survival (LRFS) and disease free survival (DFS)were 93.8\% (95\% CI, 87.8-99.8\%) and 70.2\% (95\% CI, 58.8-81.6\%, Figure 1) respectively. The 3-year overall survival rate was $89.4 \%$ (95\% confidence interval [95\% CI] $81.7-97.1 \%$; Figure 2). Four (6.4\%) patients experienced locoregional recurrence as the first site of recurrence and $22(35.5 \%)$ patients developed distant metastases. Acute toxicities were moderate during concomitant chemoradiotherapy. Five patients (8.1\%) had grade 3-4 radiation dermatitis. Grade 3-4 radiation pneumonitis developed in 2 patients. Long-term toxicity was rare.

Conclusion: Concurrent docetaxel and radiotherapyis an acceptable adjuvant regimen for patients withLABC. Although it does not apparently improve local control and/or survival, it shortened total treatment time, and was well tolerated.
\end{abstract}

Keywords: Concurrent radiation therapy, docetaxel, breast cancer

\section{Introduction}

Locally advanced breast cancer (LABC) and inflammatory breast cancer refer to a diverse and heterogeneous group of breast cancers. Patients with these cancers include those with operable disease at presentation (AJCC clinical stage T3 N1M0), inoperable disease at presentation (AJCC clinical stage T4 or N2 to $3 \mathrm{M} 0$ ), and inflammatory breast cancer (AJCC clinical stage T4dN0 to N3M0) [1]. This group represents only $2 \%$ to $5 \%$ of all breast cancers in the United States (1) while in Egypt, patients usually present with advanced stage of cancer [2].
Compared to patients with early breast cancer, patients with LABC are at a significantly higher risk of local recurrence and distant metastases and have a worse overall survival. According to Tumor, Nodes, Metastases (TNM) stage, five-year relative survival rates by stage for patients presenting with stage I, IIA, IIB, IIIA, IIIB, and IV disease were 95, 85, 70, 52, 48, and 18 percent, respectively [3]. Current guidelines recommend primary surgery or neoadjuvant therapy followed by surgery. Mastectomy remains the standard of care for most patients with locally advanced disease, but breast-conserving surgery can be 
considered for carefully selected patients. Adjuvant radiation to the breast, chest wall, and draining lymphatics should be offered to all patients with clinical stage III disease [4].

The optimal way to integrate chemotherapy and radiation therapy (RT) after breast surgery for patients with breast cancer remains unknown [5]. However, the current standard is chemotherapy followed by whole-breast-irradiation (WBI). The delay of RT induced more frequent local recurrences [6-8]. From pooled data of 10 retrospective studies, delaying RT in favour of chemotherapy increased the risk of local relapse to $16 \%$ from 6\% [9]. Concurrent treatment allows RT and chemotherapy to start temporally, shortens the duration of therapy, and potentially improves local control via the radiation sensitizing effects of chemotherapy [10].

Anthracyclines and taxanes are the backbone of most modern breast chemotherapy regimens. Anthracycline-based concurrent chemoradiotherapy (CCRT) has been associated with serious skin and cardiac toxicity [11]. The concurrent use of taxanes and WBI seems feasible. Taxanes are mitotic inhibitors that stabilize microtubules by promoting their assembly and preventing depolymerization $[12,13]$. After exposure to the taxanes, cells are arrested in the G2/M phase of the cell cycle, which is known to be the most radiosensitive phase of the cell cycle $[\mathbf{1 4}, \mathbf{1 5}$. Docetaxel has been studied in combination with radiation in other solid tumors with favorable results. In phase II trials, the most commonly used schedule with concomitant radiation was docetaxel at 20 to $30 \mathrm{mg} / \mathrm{m}^{2}$ per week [16].

The present study addressed the use of concurrent radiation therapy and docetaxel in adjuvant treatment of locally advanced breast cancer.

\section{Patients and methods}

Between February 2009 and Jan. 2013, 62 patients with locally advanced breast cancer who underwent primary modified radicalmastectomy (MRM) or neo adjuvant chemotherapy followed by MRMat Assiut University Hospitals were entered into this pilot prospective trial. Patients should fulfill the following criteria.

\section{Inclusion criteria}

- Histological diagnosis of invasive adenocarcinoma of the breast.

- AJCC clinical stage III at presentation.

- Age $\geq 18$ and $\leq 70$ years old.

- Performance status (Karnofsky index) $\geq 80$.

- Complete stage workup during the 4 weeks prior to the start of treatment. All patients must have baseline measurements of breast and nodallesions. All patients must have a bilateral mammogram, computed tomography (CT)-scan of the chest and abdomen and echocardiography. If there was bone pain, and/or alkaline phosphatase elevation, a bone scin tigraphy was mandatory.

- Laboratory results (within 14 days prior to the start of adju vant treatment): Hematology: neutrophils $\geq 1.5 \times 10^{\wedge} 9 / 1$; platelets $\geq 100 \times 10^{\wedge} 9 / 1$; hemoglobin $\geq 10 \mathrm{mg} / \mathrm{dl}$; Hepatic function: total bilirubin $\leq 1$ upper normal limit (UNL); SGOT and SGPT $\leq 2.5 \mathrm{UNL}$; alkaline phosphatase $\leq 2.5 \mathrm{UNL}$. Renal function: creatinine $\leq 175 \mathrm{umol} / \mathrm{l}(2 \mathrm{mg} / \mathrm{dl})$.

\section{Exclusion criteria}

- Prior radiotherapy for breast cancer.

- Bilateral invasive breast cancer.

- Pregnant or lactating women.

- Any M1 tumor.

- Pre-existing grade $\geq 2$ motor or sensorial neurotoxicity (National Cancer Institute Common Toxicity Criteria ver sion 2.0 [NCI CTC v-2.0]).

- Any other serious medical pathology, such as congestive heart failure; unstable angina; history of myocardial infarc tion during the previous year or high risk arrhythmias.

\section{Treatment plan}

Patients who didn't receive neoadjuvant chemotherapy were given the same regimen in the adjuvant sitting. Neoadjuvant or adjuvant chemotherapy used in this study represented a standard anthracycline-based regimen. It consisted of three cycles of intravenous 5-fluorouracil $\left(500 \mathrm{mg} / \mathrm{m}^{2}\right)$, epirubicin $(100 \mathrm{mg} /$ $\mathrm{m}^{2}$ ), and cyclophosphamide $\left(500 \mathrm{mg} / \mathrm{m}^{2}\right)$ administered every three weeks (FEC) [17].

Three to five weeks after mastectomy or after the last dose of adjuvant FEC, patients were given concurrent chemoradiotherapy. Weekly intravenously(IV) docetaxel $\left(30 \mathrm{mg} / \mathrm{m}^{2}\right)$ was given over 9 weeks, with daily external beam radiation therapy (RT) administered concurrently during the first five to six weeks.RT started the day of the first docetaxel cycle and was given at least 2 hours after finishing docetaxel infusion. All patients were premedicated with IV dexamethasone $8 \mathrm{mg}$, ondansetron $8 \mathrm{mg} \mathrm{IV}$, and ranitidine $50 \mathrm{mg} I V$ infusion 30 minutes before chemotherapy.

\section{Radiation therapy technique}

The target volumes included treatment to the chest wall and draining lymphaticswhen indicated. The supraclavicular nodal regionwas treated in patients who had 4 or more involved axillary nodes orany number of involved axillary nodes with extracapsular extension. Additional axillary radiation was given when axillary dissectionwas inadequate, defined as Level I and II nodes not resected orfewer than 10 nodes removed, and was also given when there wasgross residual disease in the axilla. The axilla was not specifically targeted for cases of extracapsular extension after lymph node dissection. Internal mammary nodes were not specifically targeted. Patients were immobilized with their ipsilateral arm abducted (90 to 120 degrees) and externally rotated. Patients were placed on a 10- to 15-degree angle board to flatten the slope of the chest wall in the region of the sternum. The border between the chest wall and the supraclavicular fields is typically placed at the bottom of the clavicular head. Treatment portals consisted of opposing tangential fields using 6- to 10-MV photons. The lateral border of this field was matched to the photon tangent fields that were 
created with matched nondivergent deep and cranial borders. A nondivergent cranial border was created through rotation of the couch, and a nondivergent deep border was achieved by overrotating the gantry or a half-beam block. The collimators were rotated to match the chest wall slope, and any volume that extended into the supraclavicular field is blocked. These fields were matched to a supraclavicular/axillary apex field. All patients were planned with two-dimensional planning. All chest wall radiation fields were designed to avoid irradiating the heart. Initial fields and target volumes were treated to a total dose of 50 Gy in 25 fractions over 5 weeks. For patients with skin involvement a $5-10-\mathrm{mm}$ bolus was applied for $50 \%$ of the dose every other day to cover skin and dermal lymphatics.

During chemoradiotherapy, patients were evaluated weekly for acute toxicity and compliance with the protocol. Clinical examination and complete blood count were performed. An absolute granulocyte count of less than $1,500 / \mathrm{mm}^{3}$ or a platelet count of less than $100,000 / \mathrm{mm}^{3}$ beforeeach cycle resulted in a treatment delay of at least 1 week. Treatment was stopped if hematologic recovery took more than 5 weeks. No dose reductions were planned. RT was interrupted if grade 3 cutaneous or pulmonary toxicity occurred.

Concerning HER2 status, none of the patients with HER2 positive disease were treated with neoadjuvant or adjuvant trastuzumab, due to financial reason. All women who were shown to have estrogen receptor-positive and/or progesterone receptor-positive tumors were prescribed $20 \mathrm{mg}$ daily of tamoxifen, which was started 3 weeks after the last dose of docetaxel.

The trial was approved by the ethics committee of the Faculty of Medicine, Assiut University, and allpatients provided a written informed consent.

\section{Follow-up and end points}

Patients were followed every three months for the first two years after the last cycle of adjuvant chemotherapy and thereafter every six months for 5 years. Mammography was performed annually. The primary end point was Disease free survival (DFS), defined as the time from enrolling in the study to the first treatment failure or death. Secondary end points were the incidence of adverse effects, local recurrence-free survival (LRFS) defined as the time from enrolling in the study to the first treatment locoregional relapseor death and overall survival (OS) calculated from the time of diagnosis to the time of the last follow-up visit or death.

\section{Toxicity evaluation}

Skin, lung and esophageal toxicities were assessed according to the Radiation Therapy Oncology Group (RTOG) scale for acute and late effects. Other toxic side effects werescored according to National Cancer Institute Common Toxicity Criteria version 2.0 [NCI CTC v-2.0].

\section{Statistical analysis}

The Kaplan-Meier method was used to estimate the rates of DFS, LRFS, and OS. Statistical analysis was performed using
SPSS for Windows version 20.0 (SPSS, Inc., Chicago, IL).

\section{Results}

Patients and disease characteristics are summarized in Table 1. Sixty-two patients were recruited in this study, 46 (74.2\%) of them underwent neoadjuvant FEC followed by MRM. All of the remaining 16 patients who underwent primary MRM received 3 cycles of adjuvant FEC. Patients in clinical stages IIIA, -B, and C were $38.7 \%, 45.2 \%$, and $16.1 \%$ respectively. No patients had inflammatory breast cancer. Underwent primary mastectomy or neoadjuvant chemotherapy followed by mastectomy. Estrogen receptor (ER)-positive expression was found in $56.5 \%$, and in $54.8 \%$ for progesterone receptor (PgR). Low/moderate histological grade was 56.5 , while high grade stood at $43.5 \%$. Human epithelial growth factor receptor 2 (HER2) expression wasfound in $27.4 \%$.

\section{Treatment compliance}

Thirty eight (61.3\%) patients received supraclavicular irradiation, and a posterior axillary supplement was used in eleven(17.7\%) patients. RT treatment had to be interrupted in 13 (21\%) patients; $5(8.1 \%)$ of them were due to skin toxicity grade 3 , six were due to machine malfunctions and two due to patient choice. Two patients received less than $50 \mathrm{~Gy}$.

Table 1. Patient and Tumor Characteristics.

\begin{tabular}{ll}
\hline Patient and Tumor Characteristics & No. of patients (\%) \\
\hline Age: median (range) months & $51.5(26-70)$ \\
\hline Menopausal status: & \\
Pre/perimenopausal & $32(51.6)$ \\
Postmenopausal & $30(48.4)$ \\
\hline T- stage & \\
T3 & $38(61.3)$ \\
T4 & $24(38.7)$ \\
\hline N- stage & \\
N0 & $5(8.1)$ \\
N1 & $19(30.6)$ \\
N2 & $23(37.1)$ \\
N3 & $15(24.2)$ \\
\hline TNM stage & \\
IIB & $15(24.2)$ \\
IIIA & $17(27.4)$ \\
IIIB & $20(32.3)$ \\
IIIC & $10(16.1)$ \\
\hline Grade & \\
I & $5(8.1)$ \\
II & $30(48.4)$ \\
III & $27(43.5)$ \\
Estrogen receptor & \\
Negative & $27(43.5)$ \\
Positive & $35(56.5)$ \\
Nrogesterone receptor & \\
Positive & $28(45.2)$ \\
HER2/neu & $34(54.8)$ \\
Negative & \\
\hline & $23(37.1)$ \\
\hline
\end{tabular}


Three patients (4.8\%) of the whole group developed grade 1-2 hypersensitivity reactions to docetaxel (in the form of palpitation and chest pressure) and they were re-challenged successfully with slower rates of infusion. Three patients discontinued docetaxel after the third to sixth weekly doses due to grade III neuropathy.

\section{Outcome and pattern of failure (Table 2)}

The median follow-up for all patients is 32 months (range 12-63). Forty-eight patients (77.4\%) remain alive,12 patients (19.4\%) died due to breast cancer, and 2 (3.2\%) from other nonrelated causes. The 3-year rate of LRFS and DFS was 93.8\% (95\% CI, 87.8-99.8\%) and $70.2 \%$ (95\% CI, 58.8-81.6\%, Figure 1). The 3-year overall survival rate was $89.4 \%$ (95\% confidence interval [95\% CI], 81.797.1\%; Figure 2). Four (6.4\%) patients experienced locoregional recurrence as the first site of recurrence and 22 (35.5\%) patients developed distant metastases. First sites of distant metastases were as follows: bone (16.1\%), lung (6.4\%), liver $(4.8 \%)$ and brain (3.2\%). Four patients had more than one recurrence site.

\section{Toxicity}

Both acute locoregional and Acute systemic toxicities were moderate during concomitant chemoradiotherapy. Table 2 shows the incidences of grade $3 / 4$ toxicities during concomitant chemoradiotherapy. Five patients $(8.1 \%)$ had grade $3-4$ radiation dermatitis. Grade 3-4 radiation pneumonitis developed in 2 patients.

Regarding docetaxel-induced systemic toxicity, seven patients (11.3\%) developed grade 3-4 neutropenia, six (9.7\%) had grade 3-4 anaemia and three (4.8\%) had grade 3-4 thrombocytopenia. Grade 3-4 neuropathy occurred in three patients. There was no grade 3-4 gastrointestinal toxicity.

Long-term toxicity was rare. Skin pigmentation and telangectasia were recorded in $8.1 \%$, and $3.2 \%$ of the study patients

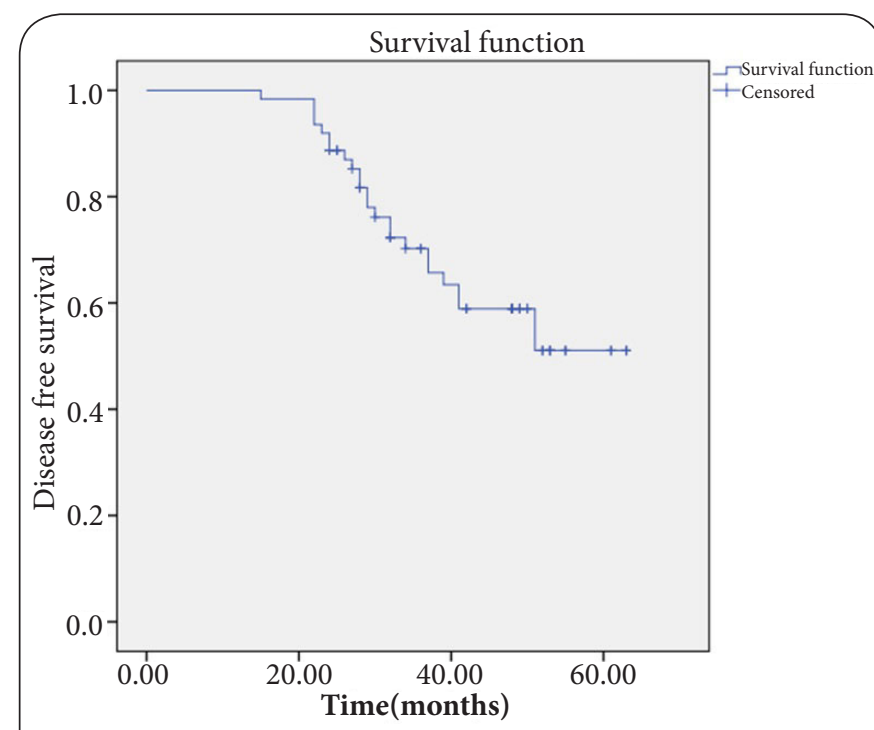

Figure 1. Disease Free survival of 62 patients with LABC receiving post-mastectomy concomitant Docetaxel and radiotherapy.

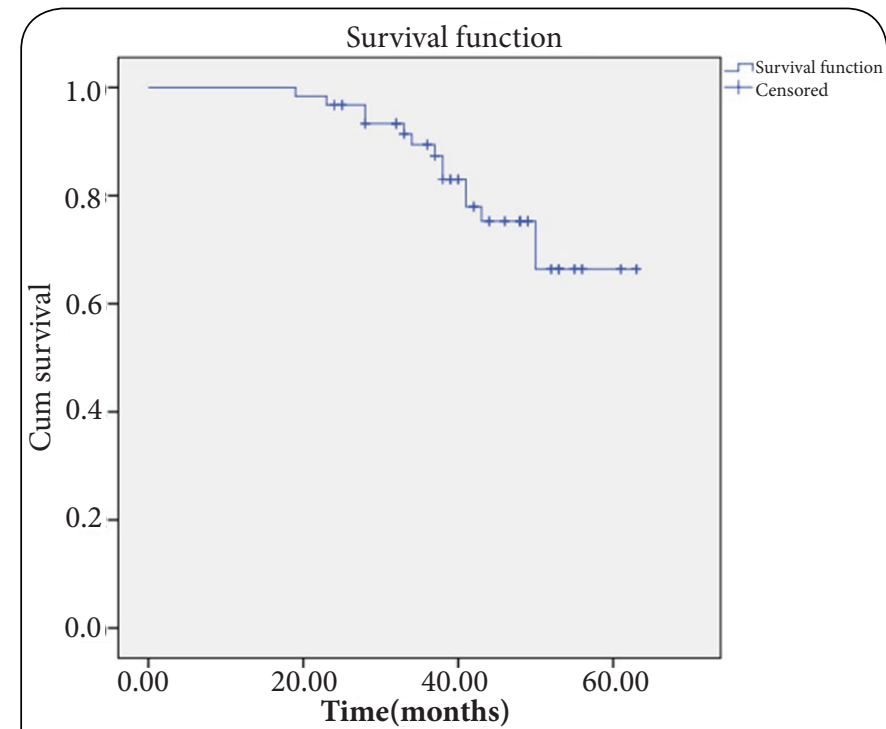

Figure 2. Overall survival of 62 patients with LABC receiving post-mastectomy concomitant Docetaxel and radiotherapy.

Table 2. Concomitant chemoradiotherapy-induced acute toxicity.

\begin{tabular}{lll}
\hline Toxicity & \multicolumn{2}{l}{ Number of patients (\%) } \\
\hline $\begin{array}{l}\text { During concomitant } \\
\text { chemoradiotherapy }\end{array}$ & All grades & Grades 3/4 \\
Radiation dermatitis & $48(77.4 \%)$ & $5(8.1 \%)$ \\
Radiation pneumonitis & $11(17.7 \%)$ & $2(3.2 \%)$ \\
Anemia & $24(38.7 \%)$ & $6(9.7 \%)$ \\
Neutropenia & $21(33.9 \%)$ & $7(11.3 \%)$ \\
Thrombocytopenia & $11(17.7 \%)$ & $3(4.8 \%)$ \\
Neuropathy & $10(16.1 \%)$ & $3(4.8 \%)$ \\
Diarrhoea & $6(9.7 \%)$ & 0 \\
Esophagitis & $6(9.7 \%)$ & 0 \\
Febrile neutropenia & $0(0 \%)$ & $0(0 \%)$ \\
\hline
\end{tabular}

respectively. Each of radiation pneumonitis, and esophagitis were recorded in $3.2 \%$ of the study patients. There were no cases of subcutaneous fibrosis, brachial plexopathy or rib fracture.

\section{Discussion}

This trial was conducted to evaluate the impact of adjuvant concurrent RT and CT in locally advanced breast cancer.The main advantages of CCRT are: 1 . delivering both treatments of CT and RT at same time; 2. Biologicalsynergy effect that can increase the efficacy of the treatment [18].

Early experiences with concurrent chemoradiation in early-stage breast cancer were evaluated in CMF-based chemotherapeutic regimens [19-22]. Although that treatment had an acceptable toxicity profile and a shortened overall treatment time, clinical benefit in terms of OS or DFS has not consistently been shown [11]. Moreover, CMF regimens are no longer commonly used.

Since that initial experience, the feasibility of concurrent 
therapy has been explored in other chemotherapy regimens. Few prospective studies investigated CCRT using anthracycline regimen [23-26]. Fiets et al., [24] showed high rate of high grade skin toxicity, and more cardiac dysfunction, and concluded that this protocol cannot be used in practice. On the other hand, a retrospective study byIsmaili et al., compared 2 adjuvant treatments using CCRT, the first with anthracycline (group A) and the second with CMF (group B). At 5 years, the isolated LRFS was significantly higher in group A compared to group B (98.7\% vs $95.3 \%$; $\mathrm{P}=0.034)$. In addition, the use of anthracycline regimenswas associated with a higher rate of 5 years EFS ( $80.4 \%$ vs $75.1, \mathrm{P}=0.057$ ). The 5 years OS was $83.2 \%$ and $79.2 \%$ in the anthracycline and CMF groups, respectively $(\mathrm{P}=0.143)$ [10]. However, these results may be explained by theeffect of anthracycline regimen and not by the use ofCCRT [26].

In a multicentre randomized trial (Arcoseintrial), CNF ( $\mathrm{mi}-$ toxantrone $12 \mathrm{mg} / \mathrm{m}^{2}$, in combination with cyclophosphamide $500 \mathrm{mg} / \mathrm{m}^{2}$ and fluorouracil $500 \mathrm{mg} / \mathrm{m}^{2}$ ) every 21 days for 6 cycles, with RT starting during cycle 1, was compared with sequential CNF and RT. Unfortunately, the concurrent regimen failed to show any benefit in 5-year DFS and OS $[\mathbf{2 7 , 2 8}]$. The 5 -year DFS was $80 \%$ in both groups; $\mathrm{P}=0.83$, LRFS was $92 \%$ in sequential versus $95 \%$ inconcurrent; $\mathrm{P}=0.76$, and $\mathrm{OS}$ was $90 \%$ in sequential versus $91 \%$ in concurrent; $\mathrm{P}=0.76$ ). Nevertheless, concurrent treatment was shown to improve local control in lymph-node-positive patients (the 5-year LRFS was $97 \%$ inconcurrent $v 91 \%$ in sequential; $\mathrm{P}=0.02$ ).

Similar results were seen in a French multicentre trial comparing concomitant CNF and RT with CEF (cyclophosphamide-epirubicin-5-fluorouracil) and sequential RT [29]. Unfortunately, mitoxantrone has been associated with high rates of leukemic transformation; it is therefore now rarely used [11].

Taxanes may be a better choice for concurrent therapy than CMF and anthracyclines because of the former's radiation sensitizing properties $[\mathbf{3 0}, \mathbf{3 1}]$. The advantages of concurrent chemoradiation with taxanes have been well documented in the treatment of other malignancies such as lung $[32,33]$. However, the published literature regarding the concurrent administration of taxanes and RT in the treatment of breast cancer consists of small trials using varying treatment schedules and doses [34-40] providing no consensus. Paclitaxel was evaluated for concurrent therapy both in the neoadjuvant and adjuvant sittings.

In the neoadjuvant sitting, two phase $\mathrm{i} / \mathrm{ii}$ prospective trials, one by Skinner et al., [41] and the second by Kao et al., [42], in 29 and 33 patientswith labc respectively, showed a benefit from concurrent paclitaxel and rt, especially in locoregional control. Skinner et al., concluded that CCRT provides significant pathological response, in up to $33 \%$ of patients with locally advanced breast cancer, but with a significant postoperative morbidity rate. With a median follow-up of 43.8 months, Kao et al., reported 4-year actuarial locoregional control, disease-free survival, and overall survival of $83 \%, 33 \%$, and $56 \%$ respectively. In the adjuvant sitting, Chen et al., [43] evaluated Concurrent paclitaxel chemotherapy and radiotherapy in 44 women with node-positive Stage II and III breast cancer. Radiotherapy was concurrent with the first 2 cycles of adjuvant paclitaxel. The 5-year DFS was $88 \%$, and OSwas $93 \%$. There were nolocal failures [43].

Although docetaxel is highly active against breast cancer and more potent than paclitaxel in promoting tubulin polymerization, it is less well studied as concurrent therapy with radiation in breast cancer. In the neoadjuvant sitting, only a few studies have been published on radiation with concurrent docetaxel in breast cancer [36,44]. Karasawa et al., investigated whether the addition of docetaxel ( $40 \mathrm{mg} / \mathrm{m}^{2}$ biweekly) to radiotherapy enhanced tumor response in patients with advanced or recurrent breast cancer. The rates of CR, PR, SD and PD for all patients were $40 \%, 37 \%, 11 \%$ and $11 \%$, respectively.CR and PR rates were $9 \%$ and $82 \%$ for advanced disease patients, $54 \%$ and $17 \%$ for recurrent patients, Overall survival rates at 1 and 2 years after treatment were $83 \%$ and $49 \%$, respectively [44]. Two other phase i/ii Canadian studies of neoadjuvant concurrent radiation with weekly docetaxel $\left(30-35 \mathrm{mg} / \mathrm{m}^{2}\right)$ in patients with locally advanced non-inflammatory breast cancer (otc 1159 and otc 1202) are under way, but have yet to report results [11]. Tapen et al., tested the feasibility of concurrent radiation with weekly docetaxel $\left(30-35 \mathrm{mg} / \mathrm{m}^{2}\right)$ in 33 post-mastectomy patients at high risk of local failure or recurrent disease. Mean TTP was 19.16 months. Five local failures occurred at 13-28 months [45].

In the current study, the 3-year OS and DFS rates were $89.4 \%$ and $70.2 \%$ respectively. These results are comparable to rates observed in a retrospective analysis done in our University [2] This analysis assessed different sequential protocols and not concomitant chemotherapy and radiotherapy in LABC. DFS was estimated at 2.5 years, and it was $83.5 \%, 82.3 \%$ and $80 \%$ for patient receiving radiation before chemotherapy [group A], sandwich [group B] and after finishing chemotherapy [group $\mathrm{C}]$ respectively ( $\mathrm{p}>0.5)$. In another similar Egyptian retrospective analysis, Abu-Hamar et al., reported 5-year OS and DFS and LRFS rates of $71.8 \%, 67.6 \%$ and $90.9 \%$ respectively [46]. A similar 3-year LRFS (93.8\%) was found in our patients indicating that no benefit was added from docetaxel as a radiosensitizer.

In our study we did not observe excessive toxicity with concurrent radiation treatment and docetaxel. Five patients (8.1\%) had grade 3-4 radiation dermatitis while grade 3-4 radiation pneumonitis developed in 2 patients. Other investigators found some what different results, most likely because of differences in the details of both the chemotherapy agents and doses and radiotherapy. No cases of pneumonitis were reported tohave occurred in a group of 202 patients treated at the Princess Margaret Hospital in Toronto with concurrent radiotherapy and CMF [22]. Five percent of patients ( 4 of 87 patients) in a report of the "triple M" program of the Royal Marsden Hospital [47] developed symptomatic radiation pneumonitis within 6 weeks of completing radiotherapy. The investigators found that the risk of pneumonitis was correlated with having $3 \mathrm{~cm}$ oflung in the tangential radiation field.

A prospective study from William Beaumont Hospital tested RT and concurrent paclitaxel $\left(175 \mathrm{mg} / \mathrm{m}^{2}\right)$ delivered every 21 
days. The authors noted that radiation pneumonitis developed in 4 patients (20\%), and $13(65 \%)$ had Grade 2 cutaneous toxicity or higher [34]. In a retrospective analysis of the Massachusetts General Hospital experience, Taghian et al., [35] reported a $15 \%$ risk of pneumonitis in 21 patients treated with concurrentpaclitaxel and radiation as compared with an institutional incidenceof $1 \%$ among women not treated with paclitaxel. Recently, Chen et al., [43] reported thatnone of 44 patients had pneumonitis requiring steroids and acute Grade 3 skin toxicity was developed in only 2 patients.

On the other hand, a retrospective analysis from the University of Washington evaluated 44 women who received RT concurrent with either paclitaxel or docetaxel chemotherapy. There were no reports of pneumonitisal though a $20 \%$ rate of Grade 3 acute skin toxicity was seen. However, this group was more heterogeneous in treatment schema [36]. Hanna et al., [34] reported a higher-than-expected rate of radiationinduced pulmonary toxicity. They noted an increased rate of toxicity among those treatedwith MRM, which may be related to RT dose/field size. In the study conducted by Tapen et al., [45], all patients had radiation dermatitis. Four patients (8\%) had grade 3 desquamation; none had grade 4 or 5 . Chest wall/ axillary or arm pain occurred in eleven patients. Grade 1-2 or grade 3 hematologic toxicity occurred in six and two patients respectively. Grade 1 neuropathy in three patients. Grade 1-2 nausea/vomiting occurred in eight patients. Grade 1-2 diarrhea occurred in three patients [45].

In accordance to the previous studies [22,34-36,43-46], late toxicity was unusual in the current trial. Skin pigmentation and telangectasia were recorded in $8.1 \%$, and $3.2 \%$ of the study patients respectively. Each of radiation pneumonitis, and esophagitis were recorded in $3.2 \%$ of the study patients. There were no cases of subcutaneous fibrosis, brachial plexopathy or rib fracture.

We acknowledge some of the limitations of the current study. First, the sample size was too small to meaningfully stratify the patients' outcome by the risk factors. Second, the follow up period was relatively short and longer period is needed to confirm our results.

\section{Conclusion}

Our study showed that concurrent docetaxel and radiotherapy is an acceptable adjuvant regimen for patients with LABC. Although it does not apparently improve local control and/or survival, it shortened total treatment time, and was well tolerated without significant pulmonary toxicity. Longer follow up and larger randomized controlled clinical trials are needed to determine whether this regimen is superior to sequential regimens and to confirm the validity of such a strategy.

\section{Competing interests}

The authors declare that they have no competing interests.

\section{Authors' contributions}

All authors shared in research design and conduction and analysis of data. The main author (AlGizawy SM) wrote the paper and had primary responsibility for final content. All authors read and approved the final manuscript.

\section{Acknowledgement}

The authors thank the patients who consented to participate in this study and their families and carers. We also thank all the colleagues who have collaborated in this study and are not included in the list of authors.

\section{Publication history}

Editors: Bechan Sharma, University of Allahabad, India.

Dario Marchetti, Baylor College of Medicine,USA.

Received: 05 December 2015 Revised: 16 January 2016

Accepted: 08 February 2016 Published: 15 February 2016

\section{References}

1. Burstein HJ, Harris JR and Morrow M. MALIGNANT TUMORS OF THE BREAST in DeVita, Hellman, and Rosenberg's Principles \&Practice of Oncology. Wolters Kluwer; Lippincott Williams \&Wilkins. 2011; 1438.

2. Abbas H, Elyamany A, Salem M, Salem A, Binziad S and Gamal B. The optimal sequence of radiotherapy and chemotherapy in adjuvant treatment of breast cancer. Int Arch Med. 2011; 4:35. I Article I PubMed Abstract | PubMed FullText

3. Bastiaannet E, Liefers GJ, de Craen AJ, Kuppen PJ, van de Water W, Portielje JE, van der Geest LG, Janssen-Heijnen ML, Dekkers OM, van de Velde CJ and Westendorp RG. Breast cancer in elderly compared to younger patients in the Netherlands: stage at diagnosis, treatment and survival in 127,805 unselected patients. Breast Cancer Res Treat. 2010; 124:801-7. | Article | PubMed

4. Buchholz TA and Haffty BG. Breast Cancer: Locally Advanced and Recurrent Disease, Postmastectomy Radiation, and Systemic Therapies in: Perez and Brady's Principles and Practice of Radiation Oncology. Lippincott Williams \& Wilkins, Philadelphia. 2008; 1307.

5. Piroth MD, Pinkawa M, Gagel B, Stanzel S, Asadpour B and Eble MJ. Sequencing chemotherapy and radiotherapy in locoregional advanced breast cancer patients after mastectomy - a retrospective analysis. $B M C$ Cancer. 2008; 8:114. | Article | PubMed Abstract | PubMed FullText

6. Hartsell WF, Recine DC, Griem KL and Murthy AK. Delaying the initiation of intact breast irradiation for patients with lymph node positive breast cancer increases the risk of local recurrence. Cancer. 1995; 76:2497-503. I PubMed

7. Buchholz TA, Austin-Seymour MM, Moe RE, Ellis GK, Livingston RB, Pelton $J G$ and Griffin TW. Effect of delay in radiation in the combined modality treatment of breast cancer. Int J Radiat Oncol Biol Phys. 1993; 26:23-35. | Article | PubMed

8. Recht A, Come SE, Gelman RS, Goldstein M, Tishler S, Gore SM, Abner $A L$, Vicini FA, Silver B, Connolly JL and et al. Integration of conservative surgery, radiotherapy, and chemotherapy for the treatment of earlystage, node-positive breast cancer: sequencing, timing, and outcome. $J$ Clin Oncol. 1991; 9:1662-7. | Article | PubMed

9. Huang J, Barbera L, Brouwers M, Browman G and Mackillop WJ. Does delay in starting treatment affect the outcomes of radiotherapy? A systematic review. J Clin Oncol. 2003; 21:555-63. I Article I PubMed

10. Ismaili N, Elmajjaoui S, Lalya I, Boulaamane L, Belbaraka R, Abahssain H, Aassab R, Benjaafar N, El Guddari Bel K, El Mesbahi O, Sbitti Y, Ismaili M and Errihani $\mathrm{H}$. Anthracycline and concurrent radiotherapy as adjuvant treatment of operable breast cancer: a retrospective cohort study in a single institution. BMC Res Notes. 2010; 3:247. I Article I PubMed Abstract | PubMed FullText

11. Mandilaras V, Bouganim N, Spayne J, Dent R, Arnaout A, Boileau JF, Brackstone $\mathrm{M}$, Meterissian S and Clemons $M$. Concurrent chemoradiotherapy for locally advanced breast cancer-time for a new paradigm? Curr Oncol. 2015; 22:25-32. | Article | PubMed Abstract | PubMed FullText

12. Manfredi JJ, Parness J and Horwitz SB. Taxol binds to cellular microtubules. J Cell Biol. 1982; 94:688-96. | Article | PubMed Abstract | PubMed FullText 
13. Parness J and Horwitz SB. Taxol binds to polymerized tubulin in vitro. J Cell Biol. 1981; 91:479-87. | Article | PubMed Abstract | PubMed FullText

14. Gueritte-Voegelein F, Guenard D, Lavelle F, Le Goff MT, Mangatal L and Potier P. Relationships between the structure of taxol analogues and their antimitotic activity. J Med Chem. 1991; 34:992-8. I PubMed

15. Schiff PB and Horwitz SB. Taxol stabilizes microtubules in mouse fibroblast cells. Proc Natl Acad Sci U S A. 1980; 77:1561-5. | PubMed Abstract I PubMed FullText

16. Kim E.S and Khuri F.R. Docetaxel and radiation as combined-modality therapy. Oncology (Williston Park). 2002; 16:97-105.

17. Roche H, Fumoleau P, Spielmann M, Canon JL, Delozier T, Serin D, Symann $M$, Kerbrat $P$, Soulie $P$, Eichler F, Viens $P$, Monnier A, Vindevoghel A, Campone M, Goudier MJ, Bonneterre J, Ferrero JM, Martin AL, Geneve J and Asselain B. Sequential adjuvant epirubicin-based and docetaxel chemotherapy for node-positive breast cancer patients: the FNCLCC PACS 01 Trial. J Clin Oncol. 2006; 24:5664-71. | Article | PubMed

18. Kouloulias VE, Dardoufas CE, Kouvaris JR, Gennatas CS, Polyzos AK, Gogas HJ, Sandilos PH, Uzunoglu NK, Malas EG and Vlahos LJ. Liposomal doxorubicin in conjunction with reirradiation and local hyperthermia treatment in recurrent breast cancer: a phase I/II trial. Clin Cancer Res. 2002; 8:374-82. | Article | PubMed

19. Arcangeli G, Pinnaro P, Rambone R, Giannarelli D and Benassi M. A phase III randomized study on the sequencing of radiotherapy and chemotherapy in the conservative management of early-stage breast cancer. Int J Radiat Oncol Biol Phys. 2006; 64:161-7. | Article I PubMed

20. Bellon JR, Shulman LN, Come SE, Li X, Gelman RS, Silver BJ, Harris JR and Recht A. A prospective study of concurrent cyclophosphamide/ methotrexate/5-fluorouracil and reduced-dose radiotherapy in patients with early-stage breast carcinoma. Cancer. 2004; 100:1358-64. | Article | PubMed

21. Livi L, Saieva C, Borghesi S, Paoletti L, Meattini I, Rampini A, Petrucci A, Scoccianti S, Paiar F, Cataliotti L, Leonulli BG, Bianchi S and Biti GP. Concurrent cyclophosphamide, methotrexate, and 5-fluorouracil chemotherapy and radiotherapy for early breast carcinoma. Int J Radiat Oncol Biol Phys. 2008; 71:705-9. | Article | PubMed

22. Isaac N, Panzarella T, Lau A, Mayers C, Kirkbride P, Tannock IF and Vallis KA. Concurrent cyclophosphamide, methotrexate, and 5-fluorouracil chemotherapy and radiotherapy for breast carcinoma: a well tolerated adjuvant regimen. Cancer. 2002; 95:696-703. | Article | PubMed

23. van der Wall E, Schaake-Koning CC, van Zandwijk N, Baars JW, Schornagel JH, Richel DJ, Rutgers EJ, Borger JH, Beijnen JH and Rodenhuis S. The toxicity of radiotherapy following high-dose chemotherapy with peripheral blood stem cell support in high-risk breast cancer: a preliminary analysis. Eur J Cancer. 1996; 32A:1490-7. | Article | PubMed

24. Fiets WE, van Helvoirt RP, Nortier JW, van der Tweel I and Struikmans $H$. Acute toxicity of concurrent adjuvant radiotherapy and chemotherapy (CMF or $\mathrm{AC}$ ) in breast cancer patients. a prospective, comparative, nonrandomised study. Eur J Cancer. 2003; 39:1081-8. | Article I PubMed

25. Clements IP, Davis BJ and Wiseman GA. Systolic and diastolic cardiac dysfunction early after the initiation of doxorubicin therapy: significance of gender and concurrent mediastinal radiation. Nucl Med Commun. 2002; 23:521-7. | Article | PubMed

26. Bedard PL, Di Leo A and Piccart-Gebhart MJ. Taxanes: optimizing adjuvant chemotherapy for early-stage breast cancer. Nat Rev Clin Oncol. 2010; 7:22-36. | Article | PubMed

27. Toledano A, Garaud P, Serin D, Fourquet A, Bosset JF, Breteau N, Body G, Azria $D$, Le Floch $O$ and Calais $G$. Concurrent administration of adjuvant chemotherapy and radiotherapy after breast-conserving surgery enhances late toxicities: long-term results of the ARCOSEIN multicenter randomized study. Int J Radiat Oncol Biol Phys. 2006; 65:324-32. | Article I PubMed

28. Toledano A, Azria D, Garaud P, Fourquet A, Serin D, Bosset JF, MinyBuffet J, Favre A, Le Floch $O$ and Calais G. Phase III trial of concurrent or sequential adjuvant chemoradiotherapy after conservative surgery for early-stage breast cancer: final results of the ARCOSEIN trial. J Clin Oncol. 2007; 25:405-10. | Article | PubMed

29. Rouesse J, de la Lande B and Bertheault-Cvitkovic F et al. On behalf of the Centre René Huguenin Breast Cancer Group. A phase III randomized trial comparing adjuvant concomitant chemoradiotherapy versus standard adjuvant chemotherapy followed by radiotherapy in operable node-positive breast cancer: final results. Int J RadiatOncolBiolPhys. 2006; 64:1072-80.

30. Hall EJ and Giaccia AJ. Radiobiology for the Radiologist. 6th ed. Philadelphia: Lippincott Williams \& Wilkins. 2006.

31. Tishler RB, Geard CR, Hall EJ and Schiff PB. Taxol sensitizes human astrocytoma cells to radiation. Cancer Res. 1992; 52:3495-7. I Article | PubMed

32. Belani CP, Choy H, Bonomi P, Scott C, Travis P, Haluschak J and Curran WJ, Jr. Combined chemoradiotherapy regimens of paclitaxel and carboplatin for locally advanced non-small-cell lung cancer: a randomized phase II locally advanced multi-modality protocol. J Clin Oncol. 2005; 23:588391. | Article | PubMed

33. Vokes EE, Herndon JE, 2nd, Kelley MJ, Cicchetti MG, Ramnath N, Neill H, Atkins JN, Watson DM, Akerley W and Green MR. Induction chemotherapy followed by chemoradiotherapy compared with chemoradiotherapy alone for regionally advanced unresectable stage III Non-small-cell lung cancer: Cancer and Leukemia Group B. J Clin Oncol. 2007; 25:1698-704. | Article | PubMed

34. Hanna YM, Baglan KL, Stromberg JS, Vicini FA and D AD. Acute and subacute toxicity associated with concurrent adjuvant radiation therapy and paclitaxel in primary breast cancer therapy. Breast J. 2002; 8:14953. I PubMed

35. Taghian AG, Assaad SI, Niemierko A, Kuter I, Younger J, Schoenthaler R, Roche $M$ and Powell SN. Risk of pneumonitis in breast cancer patients treated with radiation therapy and combination chemotherapy with paclitaxel. J Natl Cancer Inst. 2001; 93:1806-11. | PubMed

36. Bellon JR, Lindsley KL, Ellis GK, Gralow JR, Livingston RB and Austin Seymour MM. Concurrent radiation therapy and paclitaxel or docetaxel chemotherapy in high-risk breast cancer. Int J Radiat Oncol Biol Phys. 2000; 48:393-7. | Article | PubMed

37. Formenti SC, Volm M, Skinner KA, Spicer D, Cohen D, Perez E, Bettini AC, Groshen S, Gee C, Florentine B, Press M, Danenberg P and Muggia F. Preoperative twice-weekly paclitaxel with concurrent radiation therapy followed by surgery and postoperative doxorubicin-based chemotherapy in locally advanced breast cancer: a phase I/II trial. J Clin Oncol. 2003; 21:864-70. | Article | PubMed

38. Chakravarthy AB, Kelley MC, McLaren B, Truica Cl, Billheimer D, Mayer IA Grau AM, Johnson DH, Simpson JF, Beauchamp RD, Jones $C$ and Pietenpo JA. Neoadjuvant concurrent paclitaxel and radiation in stage II/III breast cancer. Clin Cancer Res. 2006; 12:1570-6. | Article | PubMed

39. Ellerbroek N, Martino S, Mautner B, Tao ML, Rose C and Botnick L. Breast-conserving therapy with adjuvant paclitaxel and radiation therapy: feasibility of concurrent treatment. Breast J. 2003; 9:74-8. | PubMed

40. Karasawa K, Katsui K, Seki K, Kohno M, Hanyu N, Nasu S, Muramatsu H, Maebayashi K, Mitsuhashi N, Haga S, Kimura T and Takahashi I. Radiotherapy with concurrent docetaxel for advanced and recurrent breast cancer. Breast Cancer. 2003; 10:268-74. | PubMed

41. Skinner KA, Silberman H, Florentine B, Lomis TJ, Corso F, Spicer D and Formenti SC. Preoperative paclitaxel and radiotherapy for locally advanced breast cancer: surgical aspects. Ann Surg Oncol. 2000; 7:145-9. | PubMed

42. Kao J, Conzen SD, Jaskowiak NT, Song DH, Recant W, Singh R, Masters GA, Fleming GF and Heimann R. Concomitant radiation therapy and paclitaxel for unresectable locally advanced breast cancer: results from two consecutive phase I/II trials. Int J Radiat Oncol Biol Phys. 2005; 61:1045-53. | Article | PubMed

43. Chen WC, Kim J, Kim E, Silverman P, Overmoyer B, Cooper BW, Anthony $\mathrm{S}$, Shenk R, Leeming R, Hanks SH and Lyons JA. A phase II study of radiotherapy and concurrent paclitaxel chemotherapy in breast-conserving treatment for node-positive breast cancer. Int J Radiat Oncol Biol Phys. 2012; 82:14-20. | Article | PubMed

44. Karasawa K, Katsui K, Seki K, Kohno M, Hanyu N, Nasu S, Muramatsu H, Maebayashi K, Mitsuhashi N, Haga S, Kimura T and Takahashi I. Radiotherapy with concurrent docetaxel for advanced and recurrent breast 
Algizawy et al. Journal of Cancer Therapeutics \& Research 2016,

http://www.hoajonline.com/journals/pdf/2049-7962-5-4.pdf

cancer. Breast Cancer. 2003; 10:268-74. I PubMed

45. Tapen E, Halberg F.E, Champion L.A, Davis CRAB, Dutton S.C and Rosenthal S.A. Treatment of locally recurrent or high-risk carcinoma of the breast with radiation therapy and weekly docetaxel given as a radiosensitizer. Journal of Clinical Oncology, 2008 ASCO Annual Meeting Proceedings (Post-Meeting Edition). 2008; 26:11538. | $\underline{\text { Article }}$

46. Abu-Hamar Ael H, Barakat AF, Elgantiry M and Nasef HH. Sequence of radiation therapy and chemotherapy as adjuvant treatment in breast cancer. J Egypt Natl Canc Inst. 2010; 22:95-104. I Pdf | PubMed

47. Fernando IN, Powles TJ, Ashley S, Grafton D, Harmer CL and Ford HT. An acute toxicity study on the effects of synchronous chemotherapy and radiotherapy in early stage breast cancer after conservative surgery. Clin Oncol (R Coll Radiol). 1996; 8:234-8. | Article | PubMed

\section{Citation:}

Algizawy S.M, Essa H.H and Zaid A.S. Concurrent radiation therapy and docetaxel in adjuvant treatment of locally advanced breast cancer. J Cancer Ther Res. 2016; 5:4.

http://dx.doi.org/10.7243/2049-7962-5-4 